\title{
An Invisible Network of Knowledge of Security and Privacy of Health
}

\author{
Cheng-Kun Wang
}

\begin{abstract}
This paper adopt scientometrics to analyse many articles's citation data and realize the paradigm shift of security and privacy of health. Privacy and security are two crucial issues in the protection of healthcare privacy. Privacy is a principle to assure that patients have more control over their health information and set limits on the use and disclosure of health information. The security is to guard data integrity, confidentiality, and availability.

By analyzing 10,218 citations of 349 articles published in SSCI and SCI journals in the security and privacy of health field from year 2003 to year 2012, this study maps the intellectual structure of security and privacy of health studies and find the development of security and privacy of health. After executing keyword analysis and tag cloud analysis, "technology", "records", "confidentiality", "internet", "communication" and "access-control" are the emerging topics in the security and privacy of health field. The contribution of this study is to provide important insights and implications of security and privacy of health. The timeline of development of security and privacy of health field reveal that protection of security and privacy of patient is very important.
\end{abstract}

Index Terms-Health care, intellectual structure, privacy, security.

\section{INTRODUCTION}

The Health Insurance Portability and Accountability Act (HIPAA) privacy and security regulations are two crucial provisions in the protection of healthcare privacy. Privacy regulations create a principle to assure that patients have more control over their health information and set limits on the use and disclosure of health information. The security regulations stipulate the provisions implemented to guard data integrity, confidentiality, and availability [1]. Patients, policymakers, providers, payers, employers, and others have increasing interest in using personal health records (PHRs) to improve healthcare costs, quality, and efficiency. Patients' greatest concern about nearly every type of electronic healthcare applications, including PHRs, is security and privacy [2].

\section{THEORETICAL DEVELOPMENT}

If I have seen further, it is by standing on the shoulders of giants (Sir Issac Newton, 1645-1736). It's said "stand on the shoulders of giants (the under-box slogan of Google Scholar $\left.{ }^{\circledR}\right)$ " in which giants means the highly cited authors,

Manuscript received January 10, 2013; revised March 12, 2013.

Cheng-Kun Wang is with the Graduate School of Business and Operations Management, Chang Jung Christian University, Taiwan (e-mail:brian19.brian19@gmail.com). papers and books. We realized that via Invisible Network of Knowledge (INK) model [3] could help a novice to navigate the blue ocean of knowledge domain when the novice knows nothing.

The past decade has especially seen extensive research on security and privacy of health. There is an area or field of security and privacy of health, the question remains somehow unclear on how it work, and what are its prospects and needs for future development.

The aim of this study is to provide security and privacy of health researchers with a unique map to better understand security and privacy of health related publications and to provide a systematic and objective mapping of different themes and concepts in the development of Security and privacy of health field. This study also attempts to help identify the linkage among different publications and confirm their status and positions in their contribution to the development of health care field.

Every discipline could be seen as a particular knowledge system that is a component of a more general knowledge system. Within each discipline, journal articles, books, and monographs fill the fundamental role of storing and distributing information. Of these three means of formal communication, journal articles are perhaps the most competitive and controversial.

Consequently, citations that appear in articles published in the journals of a particular discipline provide an objective measure of the contributions of other knowledge systems to the development and progress of that particular discipline. Citations also give a relative measure of the particular contributions of authors, articles, and journals, to the progress of a particular field of knowledge. This analysis reveals a wealth of information, for example the lists of highly-cited authors, books, and articles presented here.

\section{METHOD}

Search "security", "privacy" and "health" related journals in SSCI journals fields. Select all the papers in every 5-year peroid(2003-2007, 2008-2012) in the field, and analyze 10,218 citations of 349 articles published in SSCI journals in the security and privacy of health field from year 2003 to year 2012, this study maps the intellectual structure of security and privacy of health studies. Scientometrics can be a powerful research methodology for the understanding the epistemology of a field as it has evolved (and continue to evolve) by providing a historical timeline to follow up. Bibliometrics, timeline and tag cloud are applied to the study.

The tag cloud carries on the preliminary inquisition, pondered from the social network angle, uses the populace 
wisdom, a little at a time mounts up, or may innovate the theory and the real diagnosis, provides a new thinking direction. The tag cloud is the common display mode for the search results in folksonomy-based websites, presenting tag sizes according to the frequency and the popularity of the key words.

\section{THE FINDINGS}

After Analyzing 10,218 citations of 349 articles published in SSCI and SCI journals in the security and privacy of health field from year 2003 to year 2012, highly cited authors and papers, timeline and tag cloud are found. The detailed data includes 3,169 citations of 115 articles from year 2003 to year 2007, and 7,049 citations of 234 articles from year 2008 to year 2012. Some articles were highly cited and arranged in Table I, show the historical timeline of security and privacy of health. 5-star ranking reveals the importance of the article. Some authors are in the mainstream of security and privacy of health studies.

TABLE I: Historical Timeline of SeCurity and Privacy of Health DEVELOPMENT FROM CITATION ANANLYSIS (BIBLIOMETRICS). ANALYZING 10,218 CitATIONS OF 349 ARTICLES PUBLISHED IN SSCI AND SCI JOURNALS IN THE SECURITY AND PRIVACY OF HEALth FIELD FROM Year 2008 TO YeAR 2012. Five-STAR RANKING REVEALS the IMPORTANCE OF THE ARTICLE.

\begin{tabular}{|c|c|c|c|c|c|c|c|}
\hline 5-star & Year & $\begin{array}{l}\text { Frequency } \\
\text { Times cited }\end{array}$ & $\mathrm{B} / \mathrm{J}$ & Author & & & \\
\hline$\star \star$ & 2002 & 9 & $\mathrm{~J}$ & sweeney 1 & $\begin{array}{l}\text { int } j \text { uncertain } \\
\text { fuzz }\end{array}$ & v10 & $\mathrm{p} 557$ \\
\hline$\star \star$ & 2002 & 7 & $\mathrm{~J}$ & kim mi & $\begin{array}{l}\mathrm{j} \text { am med } \\
\text { inform assn }\end{array}$ & v9 & p171 \\
\hline$\star \star$ & 2003 & 7 & B & $\begin{array}{l}\text { cherukuri } \\
\text { s. }\end{array}$ & $\begin{array}{l}\text { proceedings } \\
2003 \\
\text { international } \\
\text { conference } \\
\text { on parallel } \\
\text { processing } \\
\text { workshops }\end{array}$ & & \\
\hline$\star \star$ & 2004 & 8 & $\mathrm{~J}$ & blobel b & $\begin{array}{l}\text { int } \mathrm{j} \text { med } \\
\text { inform }\end{array}$ & v73 & $\mathrm{p} 251$ \\
\hline $\begin{array}{l}\star \star \star \star \\
\star\end{array}$ & 2006 & 18 & $\mathrm{~J}$ & $\operatorname{tang} \mathrm{pc}$ & $\begin{array}{l}\mathrm{j} \text { am med } \\
\text { inform assn }\end{array}$ & v13 & p121 \\
\hline$\star \star \star \star$ & 2006 & 11 & $\mathrm{~J}$ & poon ccy & $\begin{array}{l}\text { ieee commun } \\
\text { mag }\end{array}$ & v44 & $\mathrm{p} 73$ \\
\hline$\star \star$ & 2006 & 7 & $\mathrm{~J}$ & $\begin{array}{l}\text { chaudhry } \\
\text { b }\end{array}$ & $\begin{array}{l}\text { ann intern } \\
\text { med }\end{array}$ & $\begin{array}{l}\text { v14 } \\
4\end{array}$ & p742 \\
\hline$\star \star$ & 2007 & 7 & $\mathrm{~J}$ & ralston jd & $\begin{array}{l}\mathrm{j} \text { am med } \\
\text { inform assn }\end{array}$ & v14 & p798 \\
\hline$\star \star \star$ & 2008 & 10 & $\mathrm{~J}$ & kaelber dc & $\begin{array}{l}\mathrm{j} \text { am med } \\
\text { inform assn }\end{array}$ & v15 & p729 \\
\hline$\star \star$ & 2008 & 8 & $\mathrm{~J}$ & lee wb & $\begin{array}{l}\text { ieee } \operatorname{tinf} \\
\text { technol b }\end{array}$ & v12 & p34 \\
\hline$\star \star$ & 2009 & 7 & $\mathrm{~J}$ & kahn js & health affair & v28 & p369 \\
\hline
\end{tabular}

Table II, Fig. 1 and Fig. 2 show keyword analysis and tag cloud analysis, "technology", "records", "confidentiality", "internet", "communication" and "access-control" are the emerging topics in the security and privacy of health field.
TABLE II: KEYWORD ANALysis AND TAG Cloud ANALysis, "TECHNOLOGY", "RECORDS", "CONFIDENTIALITY", "INTERNET", “COMMUNiCATION" AND "ACCESS-CONTROL” ARE THE EMERgING TOPICS IN THE SECURITY AND PRIVACY OF HEALTH FIELD.

\begin{tabular}{|c|c|c|c|c|}
\hline year2003-2007 & $\begin{array}{l}\text { Times } \\
\text { cited }\end{array}$ & year2008-2012 & $\begin{array}{c}\text { Times } \\
\text { cited }\end{array}$ & $\begin{array}{l}\text { increased } \\
\text { importance }\end{array}$ \\
\hline Name & Frequency & Name & Frequency & \\
\hline security & 14 & privacy & 28 & \\
\hline privacy & 12 & security & 27 & \\
\hline systems & 10 & care & 26 & \\
\hline information & 10 & technology & 17 & important \\
\hline care & 9 & health & 16 & \\
\hline health & 8 & systems & 15 & \\
\hline quality & 7 & information & 13 & \\
\hline confidentiality & 5 & records & 11 & important \\
\hline technology & 5 & confidentiality & 11 & important \\
\hline internet & 4 & system & 9 & \\
\hline access & 4 & internet & 9 & important \\
\hline information-systems & 3 & communication & 9 & important \\
\hline services & 3 & health-care & 8 & \\
\hline general-practice & 3 & management & 8 & \\
\hline management & 3 & access-control & 8 & important \\
\hline health information & 3 & design & 8 & \\
\hline public-health & 3 & impact & 7 & \\
\hline medical-records & 3 & quality & 7 & \\
\hline model & 3 & medical-records & 6 & \\
\hline
\end{tabular}
communication confidentiality electronic enty general-practice health information-systems internet issues law management medicalrecords model order patient personal physician policy privacy posen public-health quality secord
systems services

Fig. 1. Tag cloud analysis on keywords of the article from 2003 to 2007 


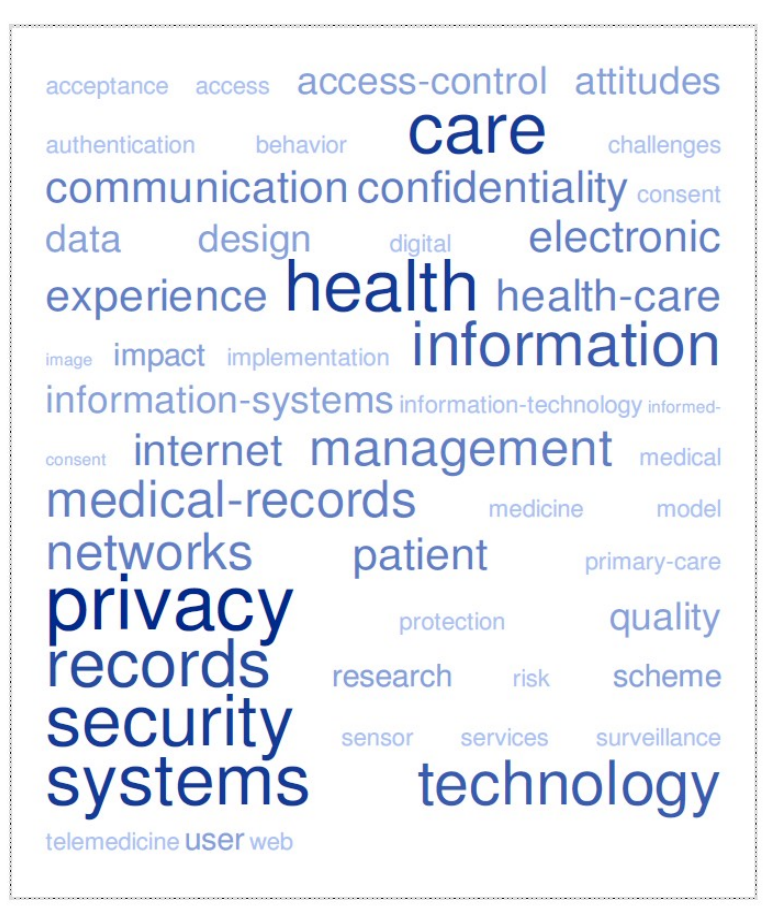

Fig. 2. Tag cloud analysis on keywords of the article from 2008 to 2012 . Keyword analysis and tag cloud analysis, "technology", "records", "confidentiality", "internet", "communication" and "access-control" are the emerging topics in the security and privacy of health field.

Table III reveals citation analysis (bibliometrics) result and shows the epistemology of a field as it has evolved (and continue to evolve), Sweeney 1 and Blobel $b$ are always in the mainstream. Tang pc (2006), Poon ccy (2006), Kaelber dc (2008) and Lee wb (2008) join the evolving trend.

TABLE III: CitATION ANANLYSIS (BIBLIOMETRICS). ANALYZING 10,218 CitATions of 349 ARTiCLES PUBLiSHED IN SSCI AND SCI JOURNALS IN THE SECURITY AND PRIVACY OF HEALTH FIELD FROM YEAR 2003 TO YEAR 2012. UNDERSTAND THE EPISTEMOLOGY OF A FIELD AS IT HAS EVOLVED (AND CONTINUE to Evolve), SWEeney l AND Blobel B ARE AlWAys IN THE Mainstream. TANG PC (2006), PoON CCY (2006), KAELBER DC (2008) AND LEE WB (2008) JOIN THE EVOLVING TREND.

\begin{tabular}{lrl}
\hline \hline Year 2008-2012 & $\begin{array}{r}\text { Times } \\
\text { cited }\end{array}$ & $\begin{array}{l}\text { increased } \\
\text { importance }\end{array}$ \\
\hline Author's Name and Article & Frequency \\
\hline
\end{tabular}

tang pc, 2006, j am med inform assn, v13, p121, doi 10.1197/jamia.m2025

18 important

poon ccy, 2006, ieee commun mag, v44, p73, doi 10.1109/mcom.2006.1632652

11 important

kaelber dc, 2008, j am med inform assn, v15, p729, doi 10.1197/jamia.m2547

10 important

sweeney 1, 2002, int j uncertain fuzz, v10, p557, doi $10.1142 / \mathrm{s} 0218488502001648$

main stream

blobel b, 2004, int j med inform, v73, p251, doi 10.1016/j.ijmedinf.2003.11.018

8 main stream

lee $w b, 2008$, ieee $t$ inf technol b, v12, p34, doi 10.1109/titb.2007.906101

\section{CONCLUSION}

This study investigates security and privacy of health by analyzing 10,218 citations of 349 articles published in SSCI and SCI journals in the security and privacy of health field from year 2003 to year 2012. The detailed data includes 3,169 citations of 115 articles from year 2003 to year 2007 , and 7,049 citations of 234 articles from year 2008 to year 2012. Patients' greatest concern about nearly every type of electronic healthcare applications, including PHRs, is security and privacy [2] .

Privacy concerns in healthcare apply to both paper and electronic records. Recent revelations of "secure" data breaches at centralized data repositories, in banking and other financial institutions, in the retail industry, and from government databases, have caused concern about storing electronic medical records in a central location. Records that are exchanged over the Internet are subject to the same security concerns as any other type of data transaction over the Internet. The Health Insurance Portability and Accountability Act (HIPAA) were passed in the US in 1996 to establish rules for access, authentications, storage and auditing, and transmittal of electronic medical records. This standard made restrictions for electronic records more stringent than those for paper records. However, there are concerns as to the adequacy of these standards [4]. Threats to health care information can be categorized under three headings: 1.Human threats, such as employees or hackers. 2. Natural and environmental threats, such as earthquakes, hurricanes and fires. 3. Technology failures, such as a system crashing.

In 2002, Kim focuses on personal health records. Web-based applications have been developed that allow patients to enter their own information into secure personal health records. Future development of PHRs should be guided by patient-oriented research targeted to evaluate the performance and usability of evolving applications [5]. In 2002, Sweeney focuses on model for protecting privacy [6].

In 2004, Blobel focuses on authorisation and access control for electronic health record systems. For enabling international communication of personal health information, securityand safetyrelated basic concepts, aggregations, relations network, and business concepts must be specified and modelled byinternational domain experts [7].

In 2006, Tang focuses on PHR's definitions, benefits, and strategies for overcoming barriers to adoption. Other barriers to PHR adoption involve legal concerns on the part of providers and the privacy concerns of individuals [8]

In 2007, Ralston focuses on patient web services integrated with a shared medical record. Tight integration of Web services with clinical information systems and patient-provider relationships may be important in meeting the needs of patients[9]. In 2008, Kaelber focuses on the Research Agenda for Personal Health Records (PHRs) and mention the PHR related privacy and security [2] . In 2008, Lee focuses on cryptographic key management solution for Privacy/Security Regulations. The Health Insurance Portability and Accountability Act (HIPAA) privacy and security regulations are two crucial provisions in the protection of healthcare privacy. Privacy regulations create a principle to assure that patients have more control 
over their health information. The security regulations stipulate the provisions implemented to guard data integrity, confidentiality, and availability. The cryptographic mechanisms are well defined to provide suitable solutions [1].

In 2009, Kahn focuses on characteristics of the ideal personal health record. Privacy issues are complex in part because newPHRs are not necessarily covered by the HIPAA regulations. An important policy implication is the protection of online health information and developing the tools for secure data exchange [10].

Tag cloud analysis was used to trace the development path of security and privacy of health research.

After executing keyword analysis and tag cloud analysis of 10,218 citations of 349 articles published in SSCI and SCI journals in the security and privacy of health field from year 2003 to year 2012, "technology", "records", "confidentiality", "internet", "communication" and "access-control" are the emerging topics in the security and privacy of health field. In the future, the main stream study of security and privacy of health may focus on "confidentiality", "internet", "communication" and "access-control".

Patients' greatest concern about nearly every type of electronic healthcare applications, including PHRs, is security and privacy. The contribution of this study is to provide important insights and implications of security and privacy of health.

\section{REFERENCES}

[1] W. B. Lee and C. D. Lee, "A cryptographic key management solution for HIPAA privacy/security regulations," Information Technology in Biomedicine, IEEE Transactions, vol. 12, pp. 34-41, 2008.
[2] D. C. Kaelber, A. K. Jha, D. Johnston, B. Middleton, and D. W. Bates, "A research agenda for personal health records (PHRs)," Journal of the American Medical Informatics Association, vol. 15, pp. 729-736, 2008.

[3] H. Etemad and Y. Lee, "The knowledge network of international entrepreneurship: Theory and evidence," Small Business Economics, vol. 20, pp. 5-23, 2003.

[4] T. Wafa, "How the Lack of Prescriptive Technical Granularity in HIPAA Has Compromised Patient Privacy," North Illinois University Law Review, vol. 30, 2010.

[5] M. I. Kim and K. B. Johnson, "Personal health records evaluation of functionality and utility," Journal of the American Medical Informatics Association, vol. 9, pp. 171-180, 2002.

[6] L. Sweeney, "k-anonymity: A model for protecting privacy," International Journal of Uncertainty, Fuzziness and Knowledge-Based Systems, vol. 10, pp. 557-570, 2002.

[7] B. Blobel, "Authorisation and access control for electronic health record systems," Int. J. Med. Inf., vol. 73, pp. 251-258, 2004.

[8] P. C. Tang, J. S. Ash, D. W. Bates, J. M. Overhage, and D. Z. Sands, "Personal health records: definitions, benefits, and strategies for overcoming barriers to adoption," Journal of the American Medical Informatics Association, vol. 13, pp. 121-126, 2006.

[9] J. D. Ralston, D. Carrell, R. Reid, M. Anderson, M. Moran, and J. Hereford, "Patient web services integrated with a shared medical record: patient use and satisfaction," Journal of the American Medical Informatics Association, vol. 14, pp. 798-806, 2007.

[10] J. S. Kahn, V. Aulakh, and A. Bosworth, "What it takes: characteristics of the ideal personal health record," Health Aff., vol. 28, pp. 369-376, 2009.

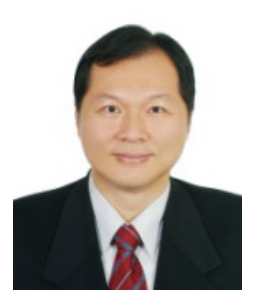

Cheng-Kun Wang is a doctoral student at the Graduate School of Business and Operations Management, Chang Jung Christian University in Taiwan. He is a medical doctor. He studied EMBA degree from the National Cheng Kung University in Taiwan. His research interests include health care and strategy. 